\title{
PELOS FIOS DAS MEMÓRIAS DO LIVRO E DA LEITURA: O ARQUIVO ZILA DA COSTA MAMEDE
}

\author{
C. J. S. Machado ${ }^{1}$, L. M. F. Fialho ${ }^{2}$ e L. M. Vasconcelos ${ }^{3}$ \\ ${ }^{1,3}$ Universidade Federal da Paraíba \\ ${ }^{2}$ Universidade Estadual do Ceará \\ E-mail: charlitonlara@yahoo.com.br ${ }^{1}$, lia_fialho@yahoo.com.br ${ }^{2}$, meiravasconcelos@gmail.com ${ }^{3}$
}

Artigo submetido em outubro/2013 e aceito em novembro/2013

\section{RESUMO}

O artigo objetiva biografar Zila da Costa Mamede, escritora, poetisa e bibliotecária, enfatizando seu protagonismo no universo cultural da produção, organização e circulação do livro no Brasil. Por intermédio da abordagem teórico-metodológica da Nova História Cultural, destacam-se as principais contribuições educacionais de Mamede, com suporte na análise de fontes documentais diversas que possibilitam compreender o seu trabalho em prol da expansão das bibliotecas brasileiras, particularmente as do Rio Grande do Norte, com o objetivo de romper os limites de uma cultura elitista predominante do saber. Ao promover maior interação e compartilhamento das instituições formais do saber e a comunidade de leitores, Zila Mamede se imortalizou como intérprete de inquietações humanísticas e literárias de sua época, destacando-se como pioneira na área da Biblioteconomia no Rio Grande do Norte.

PALAVRAS-CHAVE: biografia, educação, biblioteca, história.

\section{THROUGH THE MEMORIES, BOOK AND READING' THEAD: THE ARCHIVE ZILA DA COSTA MAMEDE}

\begin{abstract}
The article aims making the biography of Zila Costa Mamede, who was writer, poet and librarian, emphasizing her role in the cultural universe of the production and circulation of the book in Brazil. Through theoretical and methodological approach of the New Cultural History, we highlight the main educational contributions of Mamede by means of the analysis of various documentary sources that enable understand her work for the expansion of Brazilian libraries,
\end{abstract}

particularly those in Rio Grande do Norte, with the aim of breaking the boundaries of an elitist and predominant culture of know. To promote greater interaction and sharing between the formal institutions of learning and the community of readers, Zila Mamede is immortalized as an interpreter of literary and humanistic concerns of his time, especially as a pioneer in the field of librarianship in Rio Grande do Norte.

KEYWORDS: biography, education, library, history. 


\section{PELOS FIOS DAS MEMÓRIAS DO LIVRO E DA LEITURA: O ARQUIVO ZILA DA COSTA MAMEDE}

\section{INTRODUÇÃO}

Este trabalho resulta de reflexões coleadas em pesquisa realizada nos arquivos pessoais da escritora, bibliotecária e poetisa, Zila da Costa Mamede, na Biblioteca Central da Universidade Federal do Rio Grande do Norte, em Natal.

A busca tem por objetivo central reaver a história específica da trajetória e atuação da referida escritora no universo cultural da produção, organização e circulação do livro no Brasil, destacando suas principais contribuições educacionais.

Inscrito na abordagem teórico-metodológica da Nova História Cultural, o estudo em foco permite não apenas revisitar determinado movimento histórico e social de uma época, mediante a configuração da atmosfera da respectiva sociedade, mas também recobrir, registros, relatos e documentos de Zila da Costa Mamede, relativos a uma parcela de sua atuação profissional como escritora, poetisa e bibliotecária. Isto porque, ao mostrar os diferentes movimentos particulares da pessoa se pode desnaturalizar homogeneidades e revelar ações pertinentes que "presidiram a formação e edificação das práticas culturais [...] que modelam e modificam relações de poder." (LORIGA, 1996).

É importante ressaltar a observação de Nunes e Carvalho (1993), ao entender como profícua a aproximação entre a nova história cultural e a história da educação, em especial, pelo fato de a primeira se constituir campo de investigação de temas e objetos até então exclusivos dos historiadores da educação, a exemplo do livro, da leitura etc.

Segundo a condução da abordagem teórico-metodológica adotada nesta pesquisa e, também, por se tratar de uma tarefa demasiado ampla, neste estudo, optou-se por uma investigação em torno das seguintes fontes documentais: anotações manuscritas de Zila Mamede sobre a sua vida, s/d; carta manuscrita de Maria Alice Barroso a Zila Mamede, Rio de Janeiro, em 15 de junho de 1975; cópia de carta datilografada de Zila Mamede ao editor da Editora da Civilização Brasileira, Ênio da Silveira, em 15 de fevereiro de 1976; texto original datilografado por Zila Mamede em resposta ao Grande Ponto, de Racine Santos, s/d; seis pareceres da Escritora acerca de publicações de livros, como membro do Comitê Editorial da Fundação José Augusto, ano de 1984; Portaria № 182/83, de 22 de abril de 1983, nomeando a professora Zila da Costa Mamede como Coordenadora da Biblioteca Pública Câmara Cascudo, na Fundação José Augusto; Diário Oficial, Natal, 19 de abril de 1983, nomeando a escritora Zila da Costa Mamede como Membro Efetivo do Conselho Estadual da Cultura; livro Memória viva de Zila Mamede, com a transcrição completa da entrevista da Escritora concedida aos jornalistas Carlos Lyra, Alvamar Furtado e Celso da Silveira, no programa Memória Viva, TV Universitária, Natal, em 03 de fevereiro de 1981; livro Cartas de Drummond a Zila Mamede, organizado por Maria das Graça Aquino Santos; artigos e publicações recentes, trazendo à baila personagens, opiniões, projetos e contribuições da Escritora para as instituições educacionais do País.

Os citados documentos e livros, entre outras questões fundamentais de pesquisa, possibilitaram a demarcação de uma periodicidade histórica da vida de Zila da Costa Mamede ao longo de 40 anos, com destaque para a sua atuação entre os anos de 1970 - no fértil 
momento das suas atividades como bibliotecária e bibliógrafa, no Instituto Nacional do Livro (INL), no Distrito Federal e no Rio Grande do Norte, organizando as principais bibliotecas da cidade do Natal - e 1985, ano de sua morte.

Em especial, acerca da documentação pesquisada, lembra Mignot (2000, p.127), que "[...] arquivar a própria vida obedece a um projeto autobiográfico". Ou seja, aos poucos, a pessoa acumula papéis e passa a existir por intermédio deles. Nesse sentido, cabe salientar, também, que, mesmo considerando a importância da documentação pesquisada, ainda assim, não é possível, por meio dela, dar conta de toda a história da vida intelectual de Zila da Costa Mamede. Sabe-se, com efeito, que o exercício de reflexão e interpretação de fontes históricas, nas mãos de quem busca formar um perfil biográfico, incide, em última instância, na prerrogativa do pesquisador tomar a decisão do que deve ou não ficar para a história. (FRAIZ, 1998).

Buscou-se, pela análise dos citados documentos de e sobre Zila da Costa Mamede, elaborar uma narrativa histórica da sua trajetória no universo cultural da produção, organização e circulação do livro no Brasil, estabelecendo sua aproximação com o cenário da dinâmica sociocultural de uma época (LÉVI, 1996).

Pretende-se, portanto, com este estudo, ampliar o conhecimento sobre o papel inovador desempenhado por Zila da Costa Mamede como escritora, bibliotecária, bibliográfa e, por conseguinte, suas contribuições à educação brasileira, com procedência numa pesquisa biográfica, que reflete acerca da história de vida de Mamede, considerando as subjetividades inerentes à trajetória profissional.

\section{LEITURA INICIAL...}

No momento em que se comemoram os 85 anos de nascimento de Zila da Costa Mamede ${ }^{1}$, já é possível constatar significativa produção acadêmica (artigos, dissertações, teses, livros etc.) acerca da sua obra como bibliotecária ou poetisa, revelada nas instituições por onde passou, tais como o Instituto de Educação do Rio Grande do Norte, a Sociedade Cultural Brasil - Estados Unidos, em Natal, o Departamento de Recursos Humanos da SUDENE, o Instituto Nacional do Livro (INL), a Biblioteca Central da Universidade Federal do Rio Grande do Norte e, por último, assessorando as bibliotecas do Estado do Rio Grande do Norte, na perspectiva da organização e divulgação das informações necessárias às atividades de ensino, pesquisa e extensão. No tocante, porém, a sua história de vida, vislumbrando a participação ativa nos movimentos intelectuais do País, ainda há carência de estudos. A memória da vida de Mamede se configura uma realidade onde se mesclam o individual e o coletivo e se possibilita uma compreensão diferenciada daquela transmitida exclusivamente por fragmentos de uma documentação tradicional, pois permite, de acordo com a dimensão social que representa, revelar aspectos outrora relegados ou esquecidos, que fazem emergir, na subjetividade, uma trajetória árdua que culminou no fomento à produção, organização e circulação do livro no Brasil.

No artigo Vida e morte de Zila Mamede, publicado em O GALO, em 1988, o então assessor cultural do Gabinete da Presidência da República e contemporâneo da escritora, Edson Nery da Fonseca, revelava:

\footnotetext{
${ }^{1}$ Zila Mamede nasceu em 15 de setembro de 1928, na cidade de Nova Palmeira-PB. 
[...] avís rara numa atividade cheia de grandes ignorâncias gerais especializadas em biblioteconomia e documentação [...] tive o privilégio de orientá-la no primeiro programa de pós-graduação em biblioteconomia da Universidade de Brasília: programa por ela concluído com um excelente catálogo anotado de algumas obras do século XVI e XVII pertencente à UNB (1965). Veio depois a pequena bibliografia sobre Xico Santeiro (1966) e a obra monumental, em 3 volumes, Luis da Câmara Cascudo: 50 anos de vida intelectual, 1918-1968, bibliografia anotada (1970). Infelizmente, já será póstuma a obra também monumental que deixou concluída sobre João Cabral de Melo Neto: uma bibliografia crítica enriquecida com o registro de todas as variantes existentes na poesia de Cabral (Em seu recente Agreste ele dedica todo um conjunto de poemas pernambucanos a Zila Mamede). (1988, p. 3).

De origem humilde, Zila Mamede teve que enfrentar muitas dificuldades para estudar. Nos anos de 1940, tendo concluído os estudos ginasiais e secundários de Comercial Básico e Técnico em Contabilidade no Rio Grande do Norte, a Escritora partiu, imediatamente, em busca da conquista do primeiro emprego. Foi, porém, nesse período, que começaram a aflorar os conflitos com as próprias expectativas de vida: "[...] faltava-me escolaridade apropriada, leituras adequadas, respostas à minha ansiedade [...] foi uma carga demasiadamente forte de angústia na pessoinha extremamente frágil e tímida que eu era" (RESPOSTAS DE ENTREVISTA A RACINE SANTOS PARA O GRANDE PONTO, DE RACINE SANTOS, p. 1, s/d). Ainda sobre a primeira profissão e os seus consequentes desencantos, afirmava a Escritora:

[...] durante sete longos anos de estudo e aplicação a uma disciplina profissionalizante que eu detestava: Contabilidade. Pois exerci a profissão de contadora no Escritório de Sérgio Severo e no Serviço Social da Indústria. Como vê: para quem queria estudar letras, embora sem saber por qual motivo, e se profissionalizava em contabilidade, imagine o caos que enfrentou [...] (Id, ibidem, p. 1, s/d).

No início dos anos de 1950, época em que se agitavam os movimentos em prol do desenvolvimento político e econômico, emergia um ambiente inovador e intelectual em favor da educação, da música, do teatro, da poesia e da leitura no Brasil. Particularmente, no Rio Grande do Norte, a década de 1950 foi caracterizada pela ascensão de jovens escritores como Celso da Silveira, Sanderson Negreiros, além da própria Zila da Costa Mamede, que teve parte das suas poesias elaboradas nessa década publicadas, anos depois, por Alves (2006).

Nesse período, em que a vida cultural adquiria um ritmo vertiginoso no Brasil, Zila Mamede retornava ao Estado do Rio Grande do Norte após uma curta temporada vivida entre as cidades de João Pessoa e Recife, sob a responsabilidade do padrinho de batismo, o médico Francisco de Medeiros Dantas, que muito influiu em sua formação intelectual. Em entrevista aos jornalistas Carlos Lyra, Alvamar Furtado e Celso da Silveira, no Programa Memória Viva, da TV Universitária - Natal, em 03 de fevereiro de 1981, declarava a escritora:

Voltei para Natal e, evidentemente, foi aí o ponto importante. Comecei a sentir uma coisa estranha, que eu chamo, hoje, de angústia. Eu chamava "saudades do céu", naquela época. Hoje, eu chamo de angústia existencial. Então comecei a ler tudo. (MAMEDE, 1987, p. 18). 
Então, Zila Mamede começava a se inserir no universo intelectual fazendo contatos com escritores, artistas e pensadores notáveis, lendo, escrevendo e participando de eventos culturais. Acerca desse período de sua vida, revelou em depoimento escrito: "[...] minha fantasia represada se soltou e eu me dediquei aos estudos como uma tábua de salvação [...] comecei a ler tudo o que me caia às mãos: era recuperar o tempo perdido. Ficção ou poesia, crítica ou teatro, valia tudo [...]". (RESPOSTAS DE ENTREVISTA A RACINE SANTOS PARA $O$ GRANDE PONTO, DE RACINE SANTOS, p. 1-2, s/d).

Convivendo com a atmosfera poética e literária da chamada geração pós-45, Zila Mamede se lançou na vida intelectual da cidade do Natal com a publicação do seu primeiro livro de poesia, Rosa de Pedra, em 1953, editorado pela Imprensa Oficial do Rio Grande do Norte, tendo, o mesmo, a acolhida e o reconhecimento da crítica. A exemplo do literato Paulo de Tarso Correia de Melo, que considerou a obra "um digno livro de estreia." (MELO.1978. p.15).

Logo após a publicação de Rosa de Pedra, os movimentos literários de Zila Mamede ganharam outros caminhos. A escritora passou a se dedicar profundamente às leituras, movida por um desejo pulsante de ampliar sua área de atuação e, por conseguinte, conhecer de perto o cenário intelectual de sua época. Ali reconheceu ter encontrado o ambiente ao qual pertencia e dedicaria toda sua vitalidade intelectual: obras, autores, traduções, escrita e leitura.

Vivamente inquieta e seduzida por novas oportunidades intelectuais, a escritora partiu nos anos de 1950 para o Rio de Janeiro, com o intuito de realizar a formação de instrução superior. Aproximou-se de grandes nomes nacionais, a exemplo de Manuel Bandeira: “[...] comecei a ler Manuel Bandeira pelos livros mais antigos dele, até que cheguei aos livros mais modernos [...] Nessa época, me deu um certo atrevimento: fiz uma carta para Manuel Bandeira [...]" (MAMEDE, 1987, p.23). Ela começava, a partir desse momento, segundo a escritora, mais do que um contato institucional, uma grande relação de amizade. Não foi à toa que coube a Bandeira, valendo-se de sua popularidade, a responsabilidade pela liberação da primeira bolsa de estudos de Zila Mamede na Biblioteca Nacional, no Rio de Janeiro, em 1955, viabilizando a sua formação superior.

A dedicação de Bandeira por Zila Mamede era de amizade paternal e intelectual, segundo ela: "[...] ele, realmente, era um pai pra mim. Ele me dava todas as duplicatas de livros que recebia [...] me tratou como uma pessoa da família e fez mais: me obrigou a estudar [...] estudar o latim, a conhecer os clássicos." (MAMEDE, 1987, p. 22). A amizade entre ambos perduraria até a morte do poeta, ocorrida em 13 de outubro de 1968.

Na Biblioteca Nacional, Zila da Costa Mamede concluiu, em 1956, o curso de Bacharelado em Biblioteconomia, com o diploma registrado na Divisão de Ensino Superior do Ministério da Educação e Cultura. Foi nesse cenário que a escritora amadureceu sua experiência acadêmica com o universo cultural do livro e da leitura no Brasil, buscando, desde então, projetar ações em favor da difusão das organizações de bibliotecas como espaços do desenvolvimento educativo, ao lado de pesquisadores e intelectuais da época, que se reuniam, permanentemente, para estudar e trocar, além de ideias, livros e escritos. 


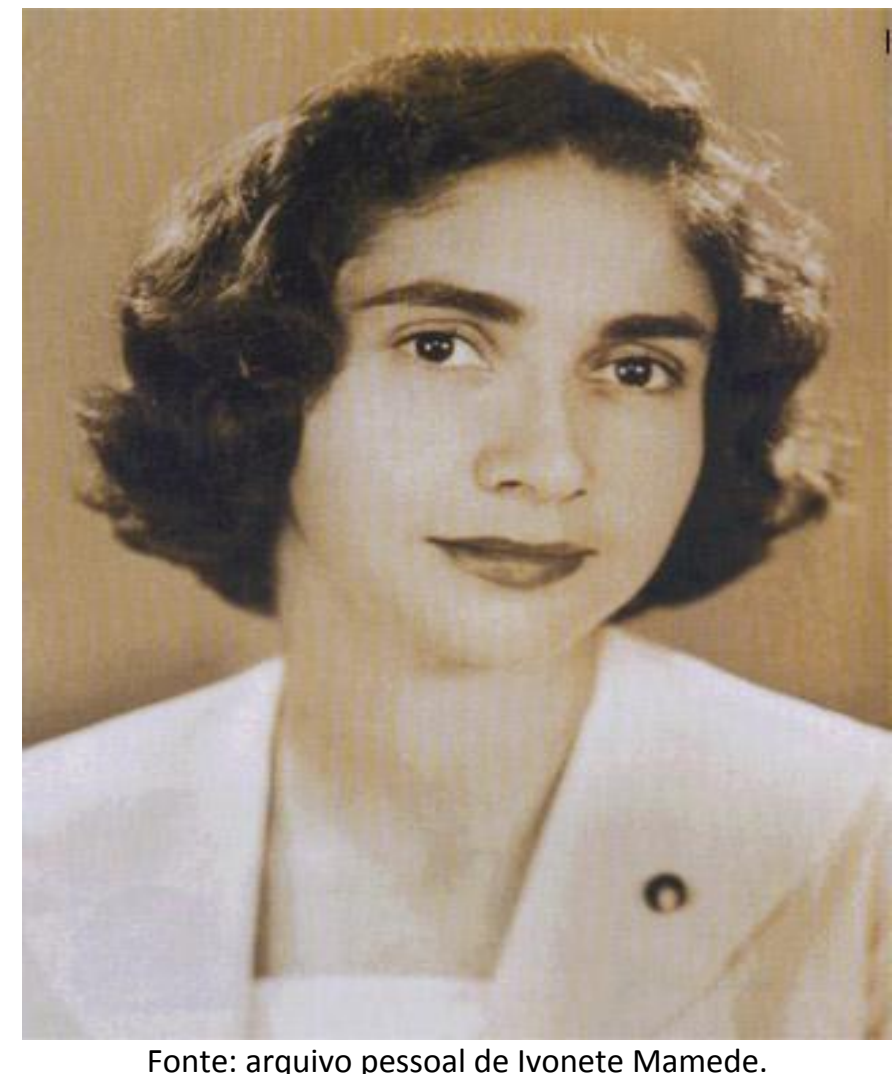

Figura 1 - Foto de Zila da Costa Mamede, início dos anos de 1950.

Assim, a temporada de formação de Zila Mamede na Biblioteca Nacional fortaleceu sua convicção intelectual como escritora, poetisa e bibliotecária, tornando-se, adiante, responsável por desenvolver diversas pesquisas, cursos e palestras na área, conduzindo suas preocupações para o fortalecimento de uma comunidade letrada, onde as bibliotecas deveriam ocupar um espaço decisivo na educação pública brasileira.

É interessante mencionar que, pertencendo a uma geração pioneira de intelectuais preocupados com a difusão do livro e da leitura no Brasil, Zila Mamede trouxe para o Rio Grande do Norte aquilo que, até então, era desconhecido: a função de bibliotecária. Assim, já naquela época, passou a lutar pela formação de mão de obra qualificada na área, por conseguinte, pelo reconhecimento da profissão como técnica e especialidade.

Desde aquele momento, mais do que uma bibliotecária, nascia em Zila Mamede uma idealizadora intelectual, preocupada em se aproximar de uma comunidade de literatos brasileiros, de socializar experiências de escrita e leitura; é o que afirmava em entrevista: "Há muita gente nova, muita gente boa, muito livro que não chega a Natal". (RESPOSTAS DE ENTREVISTA A RACINE SANTOS PARA O GRANDE PONTO, DE RACINE SANTOS, p. 3, s/d). Movida por uma preocupação de acesso ao livro e à leitura, defendia, entre outras coisas, um intercâmbio literário solidário, ou seja, um sistema de relações de doações e trocas: "uma espécie de cooperativa onde não entra dinheiro, entra livro". (Id., IBIDEM, p. 2, s/d).

Atenta a esse desafio, Zila Mamede registrava em seu depoimento o interesse e a dedicação pelo contato com as obras clássicas e inovadoras de sua época: 


\begin{abstract}
Atualmente, estou engajada no final da obra de Proust, tentei ler quatro vezes e somente agora consegui. E assim de repente me lembro dos livros de leitura paralela que mais recentemente me encantaram: Feliz ano velho, do Marcelo Rubens Paiva; A teus pés, de Ana Cristina César; O canto e as armas, de Manuel Alegre; Sociologia goiana, de Gilberto Mendonça Teles; Pagu: vida e obra, antologia organizada por Augusto Campos; Navalha na liga e Paixão chama paixão, de Alice Ruiz; A lição do amigo, cartas de Mário de Andrade a Carlos Drummond de Andrade; Cinema Pax, de Moacyr Cirne; Decisão: poemas dialéticos, de Pedro Lyra; 7 sonetos do rio, de Deífilo Gurgel; O jornal: poemas de Gastão de Holanda; Invenção de bichuim, Romanceiro de amuia, O jogo da velha, Bichuim e Contrafala, de Kátia Bento; Revangelho, Vala comum e Arquiteto do silêncio, de Dirceu Quintanilha; Amálgama e Adaga lavrada, de Lara Lemos e estou esta semana mergulhada nos poemas dos becos de Goiás e estórias de mais, de Cora Coralina." (RESPOSTAS DE ENTREVISTA A RACINE SANTOS PARA O GRANDE PONTO, p. 2).
\end{abstract}

A tarefa das leituras, ora objeto de prazer, ora objeto de investigação e trabalho científico, motivou Zila Mamede na realização dos contatos com outros escritores brasileiros contemporâneos, interessados em levar ao público obras e autores:

[...] entro nessa de trocar livros: com o Geir Campos, com a Myriam Fraga, com a Kátia Bento, com o Pedro Lyra, com a Maria de Lourdes Horta, e o Jacy Bezerra, com a Stella Leonardos, com a Heloísa Maranhão, a Eliane Zagury, a Zahidé Lupinacci Muzart, o Bandeirinha, Francisco Bandeira de Melo, do Recife [...] (Id., IBIDEM, p. 3).

Em 1957, Zila Mamede se associou à Sociedade Cultural Brasil - Estados Unidos, em Natal, tornando-se, posteriormente, sua bibliotecária e membro efetivo da sua diretoria. Nesse mesmo ano, a convite do jornal $O$ Globo, do Rio de Janeiro, acompanhou e fez a cobertura jornalística do I Congresso Internacional da Juventude Operária Católica (JOC), em Roma. Na oportunidade, aproveitou sua viagem a Europa - Espanha, Portugal, França, Itália, Alemanha, Bélgica e Holanda - para conhecer de perto as experiências culturais desses países e dos seus respectivos projetos de modernização em diversas bibliotecas (SANTOS, 1988, p. 22).

Foi, ainda, nos anos de 1950, precisamente, em 1959, no seu retorno ao Rio Grande do Norte, que Zila Mamede desenvolveu as primeiras experiências como profissional bibliotecária. Durante meses, trabalhou de forma rigorosa nas atividades de preparação, classificação e catalogação de livros e documentos que resultaram na exitosa organização da Biblioteca do Tribunal de Justiça do Estado, na Biblioteca da Faculdade de Direito da cidade do Natal, Biblioteca do Ateneu Norte-rio-grandense e da Biblioteca Pública Câmara Cascudo. Somente após algumas décadas, a sociedade viria, de fato, reconhecer o significado histórico da sua luta empreendida em favor da criação dos monumentais espaços de leitura e pesquisa nos diferentes campos de estudo.

Em plena dedicação aos estudos e às atividades profissionais como bibliotecária, lançou, em fins dos anos de 1950, outras duas grandes obras consagradas pela força e beleza da poesia, por intelectuais da época: Salinas, em 1958, publicado pelo Ministério da Educação e da Cultura, e $O$ arado, em 1959, pela renomeada Livraria São José, do Rio de Janeiro. 


\section{NOVOS RUMOS...}

No decorrer dos anos de 1960, Zila Mamede passou a se dedicar mais diretamente às atividades acadêmicas, participando de congressos na área de Biblioteconomia, lecionando, planejando bibliotecas universitárias, fazendo o curso de especialização em Administração de Bibliotecas nos Estados Unidos (Syracuse University Librany) e mestrado em Biblioteconomia na Universidade de Brasília (UNB). A pós-graduação não chegou a concluir, porém, publicou o trabalho que havia preparado como dissertação de mestrado (SANTOS, 1988).

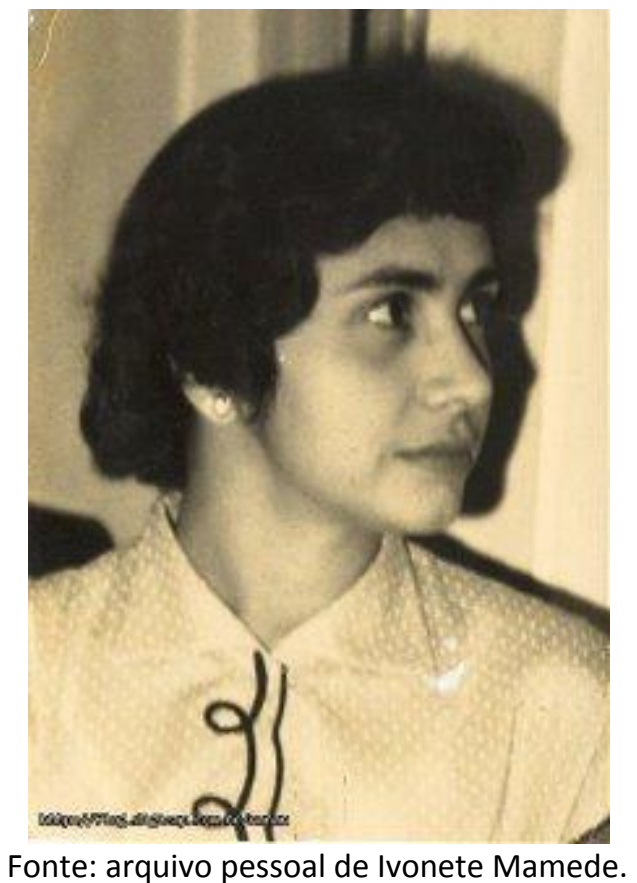

Figura 2 - Foto de Zila da Costa Mamede, início dos anos de 1960.

Envolvendo-se com a carreira de bibliotecária durante os anos de 1960, logo no início de 1970 lançou Luis da Câmara Cascudo: 50 anos de vida intelectual 1918-1968, obra que consagrou a sua carreira profissional de bibliógrafa e lhe rendeu elogios de vários intelectuais interessados em levar ao público um texto científico e sistematizado da obra do referido estudioso do folclore brasileiro. Em carta datada de 27 de março de 1967, o poeta Carlos Drummond de Andrade já indagava à Escritora sobre a publicação da referida obra:

Zila querida [...] sua bibliografia de Cascudo vai ser publicada? O homem merece esse esforço que você lhe dedicou e, principalmente, os estudiosos muito se beneficiarão com esse inventário de uma obra tão brasileira, que enriquece a todos. (Apud SANTOS, 2000, p 43).

Até meados dos anos de 1970, Zila Mamede esteve absorvida como profissional da área de Biblioteconomia, exercendo atividades permanentes de assessoria na organização do Instituto Nacional do Livro (INL), no Distrito Federal, na condição de assessora técnica, bibliotecária e coordenadora dos livros literários. Paralelamente, atuou como membro do Conselho Editorial do referido Instituto, espaço em que adquiriu experiência com editores, livrarias, escritores e leitores, como revelava em carta, datada de 15 de fevereiro de 1976, ao então editor da Civilização Brasileira, Ênio Silveira: 
[...] a experiência editorial do INL, experiência em que vivi de perto os mais diversos problemas que afligem a classe editorial bem como os produtores (os autores) da nossa literatura. Entretanto, se eu continuar pensando nesses problemas, jamais sairei deles, pois eles são insolúveis, bem o sei [...]

Zila Mamede se referia de forma crítica à restrita produção editorial do País, seus limites e obstáculos, em face da priorização de publicação de algumas obras e autores imposta pelo crivo do mercado do livro nacional, algo que dificultava, sobremaneira, a inovação literária brasileira.

\section{UM NOVO RETORNO AO RIO GRANDE DO NORTE}

Ainda nos anos de 1970, a Escritora retornou ao Rio Grande do Norte, envolvendo-se em cursos de formação bibliotecária e na ambiciosa organização das bibliotecas da cidade do Natal, principalmente na UFRN, onde pleiteava sua efetivação como profissional. Sobre essa questão, comentava a escritora e amiga Maria Alice Barroso: “[...] soube por Hélio Pontes que você está em plena batalha da indicação do Reitor [...] terminando por optar, nomeando algum nome de respeito". (CARTA DE MARIA ALICE BARROSO À ZILA MAMEDE, 15 DE JUNHO DE 1975).

Nessa mesma carta, a Escritora e ex-presidente do INL reconhece o legado de dedicação e competência da amiga e assessora Zila Mamede na referida instituição, lamentando, também, a sua partida e, revelando, ainda, os rumos e as tensões institucionais da época, com a sua substituição pelo escritor Herberto Sales:

Zila queridíssima [...] as notícias que tenho do INL, de um modo geral, são tristíssimas. O que nos custou todo um esforço para construir, está sendo fácil (ou já foi?) e rapidamente destruído [...] tudo isso me causa amargura, embora saiba, sobejamente, que se trata de fato corriqueiro nestes brasis - o sucessor destruir a obra do antecessor só para dar a impressão de que nada valia a pena [...] (Id., IBIDEM).

Por sua experiência e dedicação profissional, Zila Mamede escreveu na orelha do livro Exercício da palavra, em 1975, um balanço da sua curta presença vivida no INL e descrevia o que desejaria para a sua vida após a aposentadoria:

De 1972 a 1974, na Coordenação do livro literário, do INL, vivi e convivi com a literatura brasileira, com os autores, com os editores, com os distribuidores e pude aprender de perto o que significa a luta literária no Brasil, no sentido de produção e consumo. O que mais desejo é o dia da aposentadoria: libertação burocrática, relógio parado, dona de cada uma das horas da minha vida. Quero ver o sol nascer, ler tudo aquilo que ainda não li, andar de bicicleta, nadar, bater papo com os amigos. Haverá sempre poesia e poetas. Eu ainda escolheria uma casa de campo com meus amigos, meus livros, meus discos [...] (MAMEDE, 1975). 
Entre os anos de 1974-1980, a Escritora foi nomeada e efetivada como funcionária pública federal, período em que exerceu o cargo de Diretora da Biblioteca Central da UFRN ${ }^{2}$, tendo sido sua idealizadora e organizadora, função concluída com a sua aposentadoria, ocorrida em março de 1980.

Apesar da tão desejada aposentadoria na UFRN, a citada "libertação burocrática", Zila Mamede não encerraria naquele ano de 1980 as suas atividades profissionais, pois, no Diário Oficial do Estado do Rio Grande do Norte, datado de 19 de abril de 1983, o então governador, José Agripino Maia, publicava a nomeação da bibliotecária e escritora, com mandato de seis anos. No mesmo ano, em Portaria no 182, Natal, 22 de abril de 1983, o Presidente da Fundação José Augusto, Valério Alfredo Mesquita, nomeava "a professora Zila da Costa Mamede, para a função Diretiva de Coordenadora da Biblioteca Pública 'Câmara Cascudo', desta fundação". Em ambos os cargos, a escritora exerceu um papel de liderança na cultura intelectual regional, resultado de muita dedicação, sacrifício e trabalho, opinião partilhada por muitos de sua geração, ainda hoje.

Lendo diversos documentos pertencentes à Escritora, é possível deparar com a permanente e incansável continuidade das suas atividades profissionais, por exemplo, os seus inúmeros pareceres elaborados como membro do Comitê Editorial da Fundação José Augusto, em Natal, datados de dezembro de 1984 e início de 1985, ano de sua morte.

Por sua reconhecida contribuição e legado profissional como escritora, bibliotecária e bibliógrafa, a Biblioteca Central da UFRN passou a ser oficialmente Biblioteca Central UFRN Zila da Costa Mamede, como homenagem e reconhecimento, após a sua trágica morte, ocorrida em 13 de dezembro de 1985, levada pelas águas do rio Potengi, na Redinha, uma das praias que ela mais frequentava.

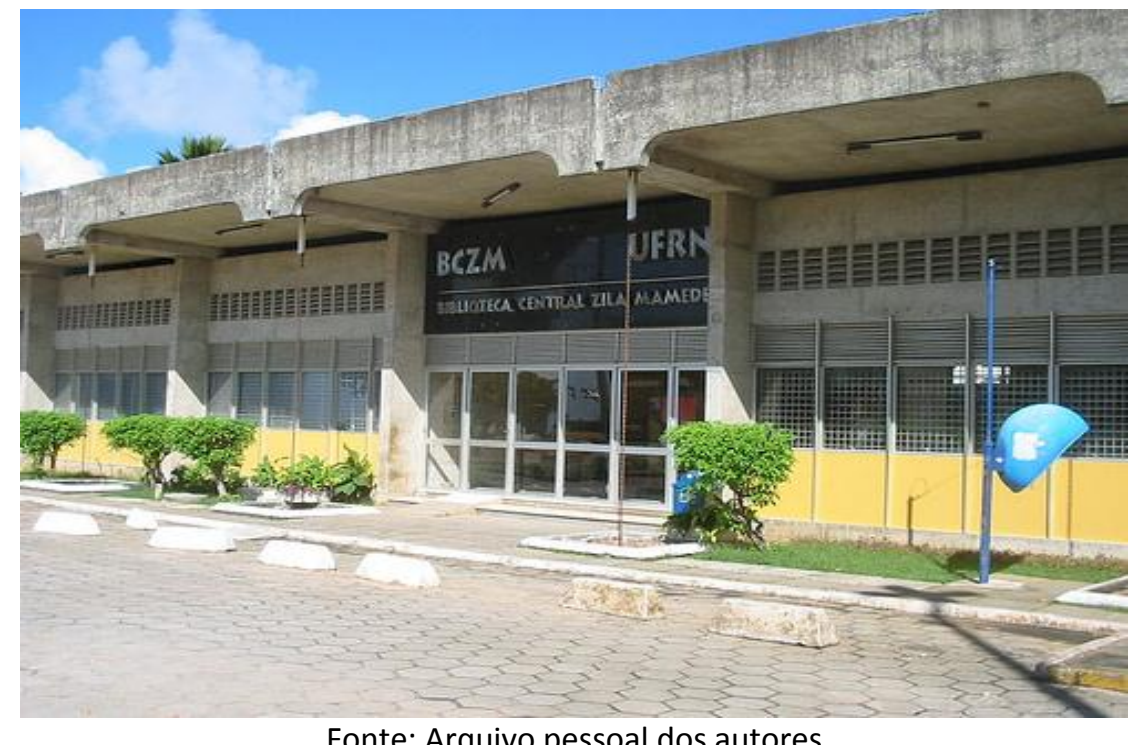

Fonte: Arquivo pessoal dos autores

Figura 3 - Foto da Biblioteca Central da UFRN Zila da Costa Mamede. Homenagem póstuma à Bibliotecária por sua histórica condição de idealizadora e organizadora do referido espaço.

\footnotetext{
${ }^{2}$ Até o ano de 1974, era denominado Serviço Central de Bibliotecas-SCB, autorizado pelo Conselho Universitário em 02.05.59. Espaço de Coordenação das atividades técnicas e administrativas das Bibliotecas das Faculdades Isoladas, passando em 1974, por idealização e organização de Zila Costa Mamede a ser Biblioteca Central da UFRN.
} 
Em coluna do jornal Tribuna do Norte, em Natal, um dia após a morte da Escritora, em 14 de dezembro de 1985, o jornalista Woden Madruga afirmava: "Sua biografia é rica, Zila, essa fantástica figura sertaneja a plantar bibliotecas, no chão árido do Nordeste". (MADRUGA, 1985, apud ALMEIDA, CASTRO, MARINHO, 2003, p. 108).

Na mesma perspectiva de reconhecimento público da obra da Escritora, Almeida, Castro e Marinho (2003, p 106) concluem que Zila Mamede foi "[...] amiga e amante do livro [...] fez da poesia e da biblioteconomia os pilares da sua vida. Sem Zila, a história da poesia e da biblioteconomia do Rio Grande do Norte seria outra". Em outro artigo, os citados escritores tributam a Zila Mamede o sucesso institucional alcançado pela Biblioteca Central da UFRN:

Apesar de ásperas e difíceis lutas, foi guiada por uma imensa vontade. Eis-nos aqui, nestes quase cinco mil metros quadrados ocupados por livros, revistas, documentos. Um templo inevitável. Um lugar de liberdade. Um canto para se ouvir. Um canto para se ficar. Um bibliocanto para desvendar, revelar e reafirmar: o homem é imaginação e desejo, sem isso nada interessa. Zila, ungida de poética e trabalho, sempre há de nos ensinar e deitar seus raios sobre nós. Nós que ainda temos medo, fome e sede. (ALMEIDA, CASTRO, MARINHO, 1994, p. 2).

Reforçando as contribuições de Zila Mamede no universo da cultura regional e nacional, Fernandes (1988, p. 17), ao analisar o conjunto da obra da referida Escritora, assinala:

Outra face do extraordinário talento de Zila Mamede é a sua produção bibliográfica, de que as pesquisas sobre Câmara Cascudo são uma amostra vigorosa. Aliás, afora o trabalho desenvolvido pelo professor Américo de Oliveira Costa, que conhece em profundidade o universo do mestre da Junqueira Aires, foi Zila, em termos provincianos, a pesquisadora mais atenta e apaixonada pelo seminal trabalho desenrolado pelo autor do 'Dicionário do Folclore Brasileiro'. Essa paixão pela pesquisa levou a criadora de 'Navegos' a executar um projeto ambicioso, da envergadura de 'Civil Geometria', que só chegou a ser editado depois da morte da poeta. Nesse livro instigante, a dedicação de Zila trouxe como resultado a mais completa reunião de textos já publicados sobre a poesia de João Cabral de Melo Neto.

Particularmente, em Civil geometria, Zila Mamede sistematizou e desenvolveu uma análise da obra de e sobre João Cabral de Melo Neto, considerada uma das mais consistentes, segundo o citado escritor, já publicadas até hoje no Brasil. Falando acerca dessa obra, afirmava a própria Zila Mamede:

Há sete anos eu me dedico à Bibliografia crítica, analítica e anotada de João Cabral de Melo Neto [...] exige dedicação até à morte, renúncia à vida social [...] estudei nesses últimos sete anos o que nenhuma universidade me ensinou [...]. (RESPOSTAS DE ENTREVISTA A RACINE SANTOS PARA $O$ GRANDE PONTO, DE RACINE SANTOS, p. 3, s/d).

A publicação póstuma da referida obra foi concretizada em 1987, pela Editora NobelSP, sendo considerada por Fernandes (1988) uma das pesquisas mais significativas do País 
sobre a obra de João Cabral de Melo Neto, ainda hoje, ocupando as estantes das principais bibliotecas brasileiras.

\title{
OBSERVAÇÕES FINAIS
}

De uma maneira geral, pode-se afirmar que Zila da Costa Mamede exerceu e lutou de forma intensa pela expansão das bibliotecas brasileiras, particularmente, as do Rio Grande do Norte, com o objetivo de romper os limites de uma dada cultura elitista predominante do saber, promovendo, assim, maior interação, maior compartilhamento entre as instituições formais do saber e a comunidade de leitores. Segundo Fonseca (1988, p. 3),

\begin{abstract}
À bibliotecária Zila Mamede ninguém poderia fazer a acusação ouvida em Jerusalém pelo apóstolo Paulo: a de que as muitas letras o faziam delirar (atos 26:24). Ao contrário, sua atividade profissional era marcada pela distinção atribuída por Fernando Pessoa ao heterônimo Álvaro de Campo, que era, como se sabe, engenheiro naval: 'Sou um técnico, mas tenho técnica só dentro da técnica. Fora disso sou doido, com todo o direito a sê-lo'. Se existe uma loucura da poesia - como existe a loucura paulina da Cruz - podese dizer de Zila Mamede que foi técnica e, ao mesmo tempo, louca.
\end{abstract}

Mais do que uma bibliotecária ou uma pesquisadora declaradamente atenta e apaixonada pelo livro, Zila Mamede foi uma intérprete de inquietações humanísticas e literárias de sua época, destacando-se como pioneira na área da Biblioteconomia no Rio Grande do Norte. Fez da sua vida profissional um desafio histórico: criar bibliotecas como espaços de saber propício não apenas para classificação, preparação, catalogação, circulação e estudos dos livros e documentos, mas, sobretudo, para a transmissão de uma cultura intelectual aberta às gerações do futuro.

Alguns anos após a sua morte, em meados dos anos de 1990, coube aos seus familiares realizarem um desejo da Escritora: fazer a doação da sua biblioteca particular à Biblioteca Central da UFRN, como forma de ampliar numa instituição educativa o acesso às pesquisas com os livros reunidos ao longo de toda a sua vida. Nela, além dos livros, encontram-se documentos, cartas, anotações e autógrafos de escritores de sua geração pós45, quanto dos mais velhos, tais como Manuel Bandeira, Carlos Drummond de Andrade, João Cabral de Melo Neto, Luis da Câmara Cascudo, amigos e incentivadores de sua produção literária.

Ao visitar o espaço onde se encontram atualmente as obras e documentos reunidos pela Escritora, na condição de pesquisador, tem-se concretamente uma demonstração da sua dedicação e interesse pela cultura literária e científica de sua época. Diversas obras estão marcadas e com inúmeras anotações, comentários, sínteses de leituras. Sobre a importância dos escritos de e sobre Zila Mamede doados por seus familiares à UFRN, conclui Fonseca (1994, p.17):

Quem não ouve o 'imortal soluço de vida' que rebenta destes livros de Zila Mamede? Reunidos agora na Biblioteca Central por ela idealizada para a sua universidade, estes livros estão felizes porque não foram disputados nos antiquários por colecionadores de autógrafos. Ninguém se iluda quanto a isto: os livros têm alma [...] Nestes livros sobrevive a memória de Zila Mamede. 
Portanto, conclui-se que as iniciativas de Zila da Costa Mamede, dentre a de outros vários intelectuais e estudiosos de sua época, contribuíram para a expansão dos espaços dos livros e das leituras no Brasil, haja vista o muito que Ihe devem a Universidade Federal do Rio Grande do Norte e outras instituições do conhecimento científico, beneficiárias de suas diversificadas práticas para a história cultural e educacional, ao longo de sua trajetória de vida profissional, seja como pesquisadora bibliógrafa, bibliotecária e escritora.

\section{REFERÊNCIAS BIBLIOGRÁFICAS}

1. ALMEIDA, Ângela; CASTRO, Marize; MARINHO, Vânia. Zila Mamede: se esse humano dos meus gestos. Natal: Editora UFRN, 2003.

2. ALVES, Alexandre. Silêncio, mar: a poesia de Zila Mamede nos anos 50. Natal: Sebo Vermelho, 2006.

3. CASTRO, Marize. Zila Mamede: poética e trabalho - imaginação e desejo. In: Bibliocanto, Ano I, n o 01, outubro de 1994, Natal: UFRN.

4. DRUMMOND, Carlos. Carta, Rio de Janeiro, 1967. In: SANTOS, Maria das Graças Aquino (Org.). Cartas de Drummond a Zila Mamede. Natal: Sebo Vermelho, 2000.

5. FERNANDES, J. Charlier. Permanência de Zila Mamede. Jornal Cultural $\mathbf{O}$ Galo, Ano I, $n$ o 02, agosto de 1988, Natal: UFRN.

6. FONSECA, Edson Nery da. Vida e morte de Zila Mamede. In: Jornal Cultural $\mathbf{O}$ Galo, Ano I, $\mathrm{n} \cong 02$, agosto de 1988, Natal: UFRN.

7. A poesia de Zila Mamede. In: Jornal Cultural 0 Galo, Ano X, $\mathrm{n} \cong 08$, setembro de 1998, Natal: UFRN.

8. Os livros de Zila. In: Bibliocanto. Informativo bimestral. Ano I, $\mathrm{n} \cong$ 01, outubro de 1994, Natal: UFRN.

9. FRAIZ, Priscila. A dimensão autobiográfica dos arquivos pessoais: o arquivo de Gustavo Capanema. Rio de Janeiro: FGV, 1998.

10. LÉVI, Giovani. Usos da biografia. In: AMADO, Janaína e FERREIRA, Marieta de Moraes (Orgs.). Usos e abusos da história oral. Rio de Janeiro: FGV, 1996.

11. LORIGA, Sabina. A experiência militar. In: LEVI, Giovanni; SCHMITT, Jean-Claude (orgs.). História dos jovens: a época contemporânea. São Paulo: Companhia das Letras, 1996.

12. MAMEDE, Zila da Costa. Memória viva de Zila da Costa Mamede. Natal: Editora Universitária UFRN, 1987.

13. . Rosa de pedra. Natal: Departamento de Imprensa, 1953.

14. Salinas. Rio de Janeiro: Departamento da Imprensa do Ministério da Educação e Cultura, 1958.

15. . O arado. Rio de Janeiro: Livraria São José, 1959.

16. Luis da Câmara Cascudo: 50 anos de vida intelectual (1918-1968). Natal: Fundação José Augusto, 1970.

17. Exercício da palavra. Natal: Fundação José Augusto, 1975.

18. N_ Navegos. Belo Horizonte: Editora Vega, 1978.

19. Civil geometria: bibliografia crítica, analítica e anotada de João Cabral de Melo Neto (1924-1982). São Paulo: Nobel, 1987.

20. MELO, Paulo de Tarso Correia de. Zila Mamede: itinerário e exercício da poesia. In: MAMEDE, Zila da Costa. Navegos. Belo Horizonte: Editora Vega, 1978. 
21. MIGNOT, Ana Chrystina Venâncio. Editando o legado pioneiro: o arquivo de uma educadora. In: MIGNOT, Ana Chrystina Venâncio; BASTOS, Maria Helena Câmara; CUNHA, Maria Teresa Santos. Refúgios do eu (Orgs.). Florianópolis: Editora Mulheres, 2000.

22. NUNES, Clarice; CARVALHO, Marta Maria Chagas de. Historiografia da educação e fontes. Cadernos ANPED, n. 0 5, set. 1993. p. 33-47.

23. SANTOS, Maria das Graças Aquino. Roteiros de uma vida: do sertão ao litoral. Natal, 1988. (mimeografado).

\section{DOCUMENTOS PESQUISADOS:}

1. Carta de Maria Alice Barroso a Zila Mamede, Rio de Janeiro, 1975.

2. De si mesma: documento manuscrito por Zila Mamede acerca da sua história de vida, s/d.

3. Cópia de Carta de Zila Mamede ao Editor da Civilização Brasileira, Ênio da Silveira, 15 de fevereiro de 1976.

4. Respostas de entrevista a Racine Santos para $O$ Grande Ponto. Documento datilografado. s/d.

5. Pareceres de publicações de livros da Fundação José Augusto, ano de 1984.

6. Portaria № 182/83, de 22 de abril de 1983, nomeando a professora Zila da Costa Mamede como Coordenadora da Biblioteca Pública "Câmara Cascudo", na Fundação José Augusto.

7. Diário Oficial, Natal, 19 de abril de 1983, nomeando a escritora Zila da Costa Mamede como Membro Efetivo do Conselho Estadual da Cultura. 